\title{
Down-Regulation of Adipogenesis and Hyperglycemia in Diet-Induced Obesity Mouse Model by Aloe QDM
}

\author{
Hyunseok Kong ${ }^{1}$, Sungwon LeE ${ }^{1}$, Seulmee SHIN ${ }^{1}$, Jeunghak Kwon ${ }^{1}$, Tae Hyung Jo ${ }^{2}$, \\ Eunju SHIN ${ }^{2}$, Kyu-Suk SHIM ${ }^{2}$, Young-In PARK ${ }^{3}$, Chong-Kil LEE ${ }^{4}$, and Kyungjae KIM ${ }^{1 \text {,* }}$ \\ ${ }^{1}$ College of Pharmacy, Sahmyook University, Seoul 139-742, ${ }^{2}$ Univera Inc., Seoul 133-120, \\ ${ }^{3}$ School of Life Sciences and Biotechnology, Korea University, Seoul 136-701, \\ ${ }^{4}$ College of Pharmacy, Chungbuk National University, Cheongju 361-763, Republic of Korea
}

(Received July 12, 2010; Revised July 20, 2010; Accepted July 22, 2010)

\begin{abstract}
Obesity-induced disorders contribute to the development of metabolic diseases such as insulin resistance, fatty liver diseases, and type 2 diabetes (T2D). In this study, we evaluated the hypoglycemic and hypolipidemic effects of aloe formula in high fat diet (HFD)-fed C57BL/6N mice. Male mice fed HFD for 28 weeks received a supplement of aloe formula, PAG, ALS, Aloe QDM, and an Aloe QDM complex for a further 8 weeks and were then compared with regular diet fed mice. After the experimental period, the blood glucose levels of the Aloe QDM complex-and PGZ-supplemented mice were significantly lower than those of the HFD-fed mice. Aloe formula, especially the Aloe QDM complex, and the PGZ treatment group profoundly affected the IPGTT and HOMA-IR. Immunochemistry was done for the morphological observation and the resulting sizes of adipocytes around the epididymis were significantly decreased when comparing the aloe formula-treated and HFD-fed groups. Further, aloe formula decreased mRNA expression of fatty acid synthesis enzymes and led to reduced hepatic steatosis in both liver and WAT. These results suggest that supplementation of Aloe QDM complex in the HFD-fed mice improved insulin resistance by lowering blood glucose levels and reducing adipocytes. Our data suggest that dietary aloe formula reduces obesity-induced glucose tolerance by suppressing fatty acid synthesis in the WAT and liver, both of which are important peripheral tissues affecting insulin resistance. The Aloe QDM complex could be used as a nutritional intervention against T2D.
\end{abstract}

Keywords: High-fat diet, Type 2 diabetes, Diet-induced obesity, Insulin sensitivity

\section{INTRODUCTION}

The prevalence of diabetes mellitus (DM), regarded as a common disorder, has been rapidly increasing since the end of the $20^{\text {th }}$ century (Rosenbloom et al., 1999; Jullien, 2008). The pathogenicity of type 2 DM, especially that induced by obesity, has been established as a chronic disease caused by inherited or acquired deficiency in insulin secretion and by decreased responsiveness of the appropriate organs to insulin (Weyer et al., 2001). Diabetes mellitus is generally classified into two main types: insulin-dependent type $1 \mathrm{DM}$ (T1D) and non-insulin-dependent type $2 \mathrm{DM}$ (T2D). The former, T1D, is characterized by an abso-

${ }^{*}$ Corresponding author

Tel: +82-2-3399-1601 Fax: +82-2-3399-1617

E-mail: kimkj@syu.ac.kr lute deficiency of insulin secretion, associated with autoimmune destruction of pancreatic $\beta$-cells, and is more likely to occur in relatives of affected persons (Srikanta et al., 1983; Zhang et al., 2001; Eizirik et al., 2009). The latter, T2D, which accounts for more than $90 \%$ of cases, is caused by a combination of resistance to insulin activity and impaired insulin secretion (Hu et al., 2001). It is a progressive disease with associated complications of retinopathy, nephropathy, neuropathy, and atherosclerosis (Marcovecchio et al., 2005). Currently available pharmacological agents for T2D exhibit a number of limitations, such as side effects and high rates of secondary failure. Thus, diabetic patients and healthcare professionals are considering complementary and alternative approaches, including the use of medicinal herbs (Attele et al., 2002; Xie et al., 2002). 
During the past 20 years, reports have shown that Aloe preparations have beneficial therapeutic effects on diabetes. The hypoglycemic effect of Aloe species was first demonstrated in 1985 by Agarwal (Agarwal, 1985). Aloe vera is a perennial plant belonging to the family of Liliaceae, which includes about 360 species (Klein and Penneys et al., 1988). It is a cactus-like plant that grows in hot, dry climates. In nature, it may be damaged physically by ultraviolet (UV) irradiation or by insects. Perhaps its survival in a harsh environment has encouraged people to believe that aloe vera has wound-healing and antibiotic effects. It is, therefore, less than fortuitous that aloe vera has been reported to possess immunomodulatory, anti-inflammatory, UV protective, anti-protozoal, and wound- and burn-healing promoting properties (Reynolds and Dweck et al., 1999). However, the actions of the functional components that are responsible for the anti-diabetic effects of aloe formula have yet to be elucidated.

Fifty years ago, Mertz and coworkers proposed that chromium $(\mathrm{Cr})$ was an essential trace element (Mertz and Schwarz et al., 1959; Schwarz and Mertz et al., 1959) and that it was required for normal carbohydrate and lipid metabolism (Anderson, 1993; Mertz, 1993; Anderson, 1995). Signs of $\mathrm{Cr}$ deficiency have been documented on numerous occasions, including elevated blood glucose, insulin, and decreased high density lipoproteins (HDL) in humans with normal diets. Herein, we used a diet-induced obesity (DIO) mouse, an animal model of type 2 diabetes (T2D), to examine whether the administration of aloe formula with $\mathrm{Cr}$ minimize the effects of hypoglycemia.

In this present study, we examined the anti-diabetic effects of aloe formula in high fat diet (HFD)-fed mice, which have been shown to closely resemble human T2D in terms of metabolic abnormalities, such as obesity and insulin resistance. Our results demonstrated that oral administration of aloe formula lowers blood glucose level and reduces gene expression of adipogenesis-associated enzymes in liver tissue and white adipose tissue (WAT) in these mice.

\section{MATERIALS AND METHODS}

\section{Chemicals and reagents}

Pocessed Aloe vera gel (PAG) (Kim et al., 2009), Aloesin (ALS), $100 \mathrm{mg} / \mathrm{kg}$ of PAG containing 2\% ALS (Aloe QDM), and Aloe QDM plus $500 \mathrm{mg} / \mathrm{kg}$ Chromiun (Cr)-enriched yeast containing $0.2 \% \mathrm{Cr}$ (Aloe QDM complex) were provided by Univera, Inc., Seoul, Republic of Korea. Pioglitazone (Actos ${ }^{\circledR}$ ) was purchased from Eli Lilly, Toronto, Canada, chromium $(\mathrm{Cr})$ was purchased from Lallemand
Inc., Montreal, Canada, glucose was purchased from Sigma Chemical Co., St. Louis, MO, USA, and all other chemicals and reagents used in this study were reagent grade.

\section{Animals and diets}

Male C57BL/6NCrjBgi mice were purchased from the Charles River Laboratory of Animal Science (Orient Co., Seoul, Republic of Korea) at four weeks old and fed a normal diet for one week. Animals were housed in individual cages with free access to water and food in a temperaturecontrolled animal facility under a $12 \mathrm{~h}$ light-dark cycle at 22 $\pm 2^{\circ} \mathrm{C}$ and $55 \pm 5 \%$ humidity. Mice were either fed a HFD (Open Source diets \#D12492; Research Diets Inc., New Brunswick, NJ) to induce obesity, or a regular diet (RD; Open Source diets \#D12450B; Research Diets Inc.). The nutritional contents of the HFD were similar to those of the regular diet except for low carbohydrate content and a high level of fat. At 26 weeks of age, mice exhibiting blood glucose levels $>160 \mathrm{mg} / \mathrm{dl}$ were selected as non-insulin-dependent diabetes mellitus (NIDDM) animals and were divided into five groups of 20 animals per group. One group was administrated with PBS only and served as diabetic controls; four groups received daily $100 \mathrm{mg} / \mathrm{kg}$ of PAG, 2 $\mathrm{mg} / \mathrm{kg}$ of ALS, Aloe QDM, and Aloe QDM complex respectively, and the fifth group was administered pioglitazone (PGZ, $2.5 \mathrm{mg} / \mathrm{kg}$ ), an anti-diabetic drug currently in clinical use. Mice were weighed and blood samples were collected weekly by tail bleeding into heparin-coated tubes after $4 \mathrm{~h}$ fasts. At the end of the experimental period, mice were sacrificed and blood samples were taken from the inferior vena cava to determine plasma insulin and lipid levels. After collecting blood, the liver, thymus, pancreas, kidney, lung, heart, and spleen were removed, rinsed with physiological saline solution, and immediately stored at $-70^{\circ} \mathrm{C}$. White adipose tissues were immediately removed from periepididymal and perirenal fat for morphological examinations. Mice were treated in accordance with the guidelines issued by Sahmyook University for the care and use of laboratory animals.

\section{Blood glucose}

Blood glucose concentrations were monitored after 4hour fasts from venous blood from the tail vein using a glucometer (MediSence Optimum, Abbott Laboratories, Bedford, USA) at 7, 14, 24, 34, 44, and 54 days of age, equivalent to days of the supplementation period.

\section{Serum collection and analysis}

Blood was collected via cardiac puncture, allowed to clot for 30 minutes, and spun at 7,000 rpm for 10 minutes. 
Isolated serum was stored at $-80^{\circ} \mathrm{C}$. Plasma insulin levels were assayed using an enzyme-linked immunosorbent assay (ELISA) kit (Shibayagi's Insulin Assay Kit, Shibayagi Co., Gunma, Japan). Homeostasis model assessment of insulin resistance (HOMA-IR) was then calculated: [(fasting blood glucose $(\mathrm{mmol} / \mathrm{L}) \times$ fasting blood insulin $(\mu \mathrm{U} / \mathrm{ml})] /$ 22.5 (Katsuki et al., 2001).

\section{Intraperitoneal glucose tolerance testing (IPGTT)}

Intraperitoneal glucose tolerance testing was performed during the last week of the experimental period. Mice who had fasted overnight received an intraperitoneal injection of glucose ( $1.5 \mathrm{~g}$ of glucose $/ \mathrm{kg}$ of body weight), and blood samples in aloe-treated groups were obtained for glucose measurement at $0,30,60,90,120$, and 150 minutes. Blood glucose was measured using a glucometer (MediSence Optimum, Abbott Laboratories, Bedford, USA) on blood collected from the tail vein after glucose administration.

\section{Analysis of triglyceride and total cholesterol levels}

Blood was collected via cardiac puncture, allowed to clot for 30 minutes, and spun at 7,000 rpm for 10 minutes. Isolated serum was stored at $-80^{\circ} \mathrm{C}$. Plasma triglyceride (TG) and total cholesterol levels were determined using a blood chemistry analyzer (Express Plus; Bayer, Pittsburgh, USA).

Frozen liver samples were homogenized, and lipid was extracted using a chloroform/methanol mixture. The hepatic TG content was determined using the method of Folch et al. (Folch et al., 1957) and Omodeo Salè et al. (Omodeo Salè et al., 1984)

\section{Histological analysis}

Adipose tissue and liver were isolated from mice, fixed in $10 \%$ formalin, and embedded in paraffin. Four-micrometers thick sections were obtained, mounted on two glassslides, and stained with hematoxylin-eosin. Sections were viewed with an Olympus microscope (Olympus, Tokyo, Japan) at $\times 200$ magnification.

\section{Isolation of total RNA and reverse transcription polymerase chain reaction (RT-PCR)}

Twenty mice were selected and used for this analysis. Liver and WAT tissues were immediately frozen in liquid nitrogen, and stored at $-70^{\circ} \mathrm{C}$ for the determination of gene transcripts. Total RNA was extracted from tissues using the RNeasy Mini kit (QIAGEN, Valencia, USA) in an RNasefree environment. RNA was then quantified by reading the absorbance at $260 \mathrm{~nm}$ as previously described (Libby et al., 2002). The reverse transcription of $1 \mu \mathrm{g}$ RNA was carried out using M-MLV reverse transcriptase (Promega, USA), an oligo (dT) 16 primer, dNTP $(0.5 \mu \mathrm{M})$, and $1 \mathrm{U}$ RNase inhibitor. After incubation at $65^{\circ} \mathrm{C}$ for $5 \mathrm{~min}$ and $37^{\circ} \mathrm{C}$ for $60 \mathrm{~min}, \mathrm{M}-\mathrm{MLV}$ reverse transcriptase was inactivated by heating at $70^{\circ} \mathrm{C}$ for $15 \mathrm{~min}$. The polymerase chain reaction (PCR) was performed in $50 \mathrm{mM} \mathrm{KCl}, 10 \mathrm{mM}$ Tris- $\mathrm{HCl}$ (pH 8.3), $1.5 \mathrm{mM} \mathrm{MgCl} 2$, and $2.5 \mathrm{mM}$ dNTPs with 5 units of Taq DNA polymerase and $10 \mathrm{pM}$ of each primer set for fatty acid synthase (FAS), stearoyl-Coenzyme A desaturase 1 (SCD-1), sterol regulatory element binding protein (SREBP)-1a (SREBP1a), and Glycerol-3-phosphate acyltransferase (GPAT). The cDNA was amplified by 35 cycles of denaturing at $94^{\circ} \mathrm{C}$ for $45 \mathrm{~s}$, annealing at $62^{\circ} \mathrm{C}$ for $45 \mathrm{~s}$, and extension at $72^{\circ} \mathrm{C}$ for $1 \mathrm{~min}$. Final extension was performed at $72^{\circ} \mathrm{C}$ for $5 \mathrm{~min}$. The PCR products were then electrophoresed on a $1.5 \%$ agarose gels and stained with ethidium bromide. The primers selected were 5' GAT CCT GGA ACG AGA ACA C 3' (forward) and 5' AGA CTG TGG AAC ACG GTG GT 3' (reverse) for FAS; 5' CGA GGG TTG GTT GTT GAT CTG T 3' (forward) and 5' ATA GCA CTG TTG GCC CTG GA 3' (reverse) for SCD-1; 5' GCG CTA CCG GTC TTC TAT CA 3' (forward) and 5' TGC TGC CAA AAG ACA AGG G 3' (reverse) for SREBP1a; 5' GGT AGT GGA TAC TCT GTC GTC CA 3' (forward) and 5' CAT CAG CAA CAT CAT TCG GT 3' (reverse) for GPAT; and 5' CAA CTT TGG CAT TGT GGA AGG 3' (forward) and 5' ATG GAA ATT GTG AGG GAG ATG C 3' (reverse) for GAPDH, which was used as an internal control.

\section{Statistical analysis}

All data have been presented as mean \pm SEM values. Significant differences $(p<0.05)$ between groups were evaluated using a one-way analysis of variance (ANOVA) with SPSS (Chicago, IL, USA) for Windows and Duncan's Multiple Range Test where appropriate.

\section{RESULTS}

\section{Decreased blood glucose levels}

The effects of the aloe formula and PGZ supplementation on blood glucose levels are shown in Fig. 1. The HFD-fed mice exhibited a significant increase in blood glucose concentrations compared with RD fed mice. Blood glucose concentrations of HFD-fed mice decreased after two weeks of administration of aloe formula and remained low at 54 days. At 54 days after treatment, a time dependent decrease in blood glucose was observed in aloe formula-treated mice, especially in Aloe QDM complex-treated mice and PGZ-treated mice. The hypoglycemic activity 


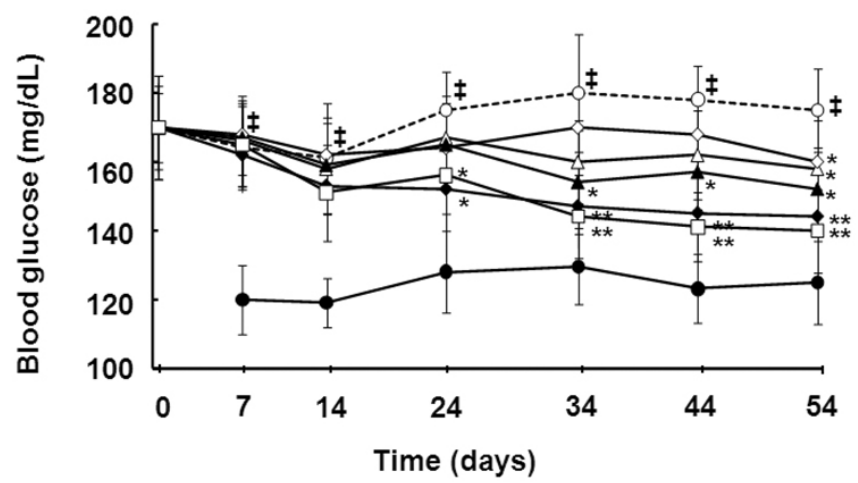

Fig. 1. Weekly changes in blood glucose concentrations in aloe formula-supplemented mice. Data are means \pm SEM.values. ${ }^{\ddagger} p$ $<0.01$ compared with RD-fed mice. ${ }^{*} p<0.05,{ }^{* *} p<0.01$ compared with untreated HFD-fed mice.

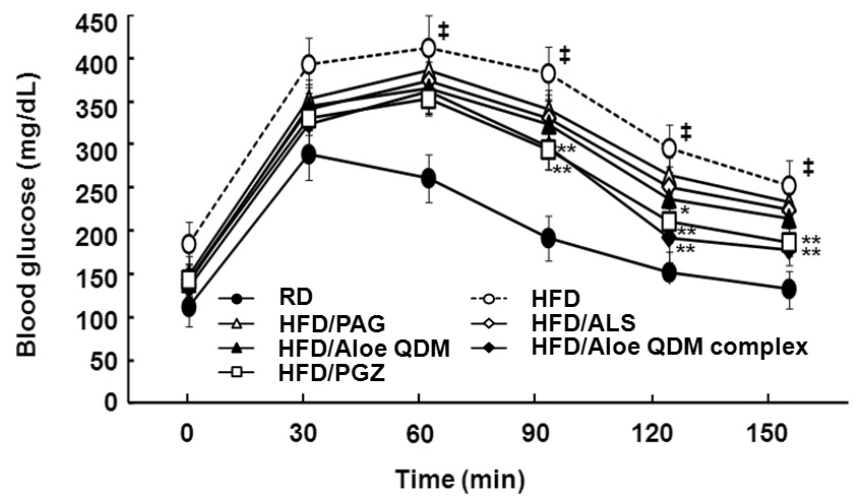

Fig. 2. Effects of aloe formula on a glucose tolerance test (GTT). GTT was done on mice that had fasted overnight and had been fed aloe formula. Data are means \pm SEM.values. ${ }^{\dagger} p$ $<0.01$ compared with RD-fed mice. ${ }^{*} p<0.05,{ }^{* *} p<0.01$ compared with untreated HFD-fed mice.

produced by aloe formula was $20 \%$ of that in HFD-fed mice.

\section{IPGTT and HOMA-IR}

As shown in Fig. 2, glucose tolerance was monitored by IPGTT at 50 days after the supplementation with aloe formula or PGZ. At time 0 , all the groups were exacerbated by the intraperitoneal glucose load. The blood glucose level in the all groups peaked at 60 minutes and recovered almost completely to the basal value at 150 minutes. Further, plasma insulin levels of HFD-fed mice were significantly (i.e., 3-fold) higher than those of RD-fed mice. Treatment of HFD-fed mice with aloe formula for eight weeks significantly reduced plasma insulin levels. Using the plasma glucose and insulin levels obtained, homeostatic model assessment values for insulin resistance were

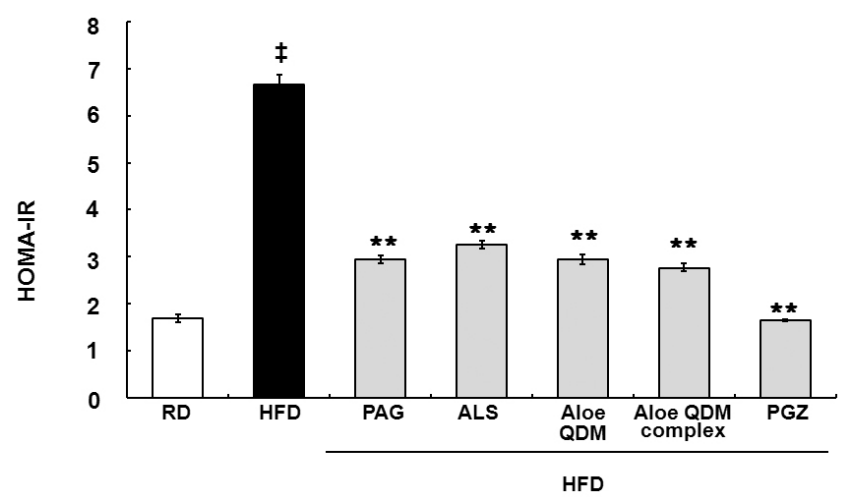

Fig. 3. Effects of aloe formula on insulin response. HOMA-IR determined from fasted serum insulin and glucose measurements. Data are means \pm SEM.values. ${ }^{\ddagger} p<0.01$ compared with RD-fed mice. ${ }^{*} p<0.05,{ }^{* *} p<0.01$ compared with untreated HFD-fed mice.

Table I. Effects of aloe formula on the serum TG, serum total cholesterol, and hepatic TG in C57BL/6N HF-fed mice

\begin{tabular}{lccr}
\hline Group & $\begin{array}{c}\text { Plasma TG } \\
(\mathrm{mg} / \mathrm{dl})\end{array}$ & $\begin{array}{c}\text { Hepatic TG } \\
(\mathrm{mg} / \mathrm{dl})\end{array}$ & \multicolumn{1}{c}{$\begin{array}{c}\text { Plasma } \\
\text { cholesterol } \\
(\mathrm{mg} / \mathrm{dl})\end{array}$} \\
\hline RD & $53.4 \pm 18.0$ & $69.0 \pm 11.5$ & $88.7 \pm 31.0$ \\
HFD & $108.5 \pm 19.0^{\mathrm{d}}$ & $314.0 \pm 134.7^{\mathrm{c}}$ & $242.4 \pm 47.0$ \\
HFD/PAG & $68.1 \pm 13.0^{\mathrm{a}}$ & $261.8 \pm 84.7$ & $241.4 \pm 42.0$ \\
HFD/ALS & $74.5 \pm 16.0$ & $204.5 \pm 44.0$ & $230.4 \pm 24.0$ \\
HFD/Aloe QDM & $69.5 \pm 14.0^{\mathrm{a}}$ & $266.0 \pm 23.3$ & $232.1 \pm 34.0$ \\
HFD/Aloe QDM & $59.5 \pm 15.0^{\mathrm{b}}$ & $220.75 \pm 35.9^{\mathrm{a}}$ & $236.8 \pm 34.0$ \\
Complex & & & \\
HFD/PGZ & $61.0 \pm 21.0^{\mathrm{a}}$ & $534.0 \pm 74.8$ & $229.8 \pm 46.0$ \\
\hline
\end{tabular}

Results are means \pm SEM $(n=20) .{ }^{a} p<0.05,{ }^{b} p<0.01$ compared with untreated HFD-fed mice, ${ }^{\mathrm{c}} p<0.05,{ }^{d} p<0.01$ compared with RD-fed mice.

calculated (Fig. 3).

\section{Reduction of plasma triglyceride and hepatic steatosis}

Liver and plasma TG and cholesterol levels for each group at the end of the eight week experimental period are shown in Table I. Triglyceride (TG) levels in the liver and plasma were significantly higher in the untreated HFD group than those of RD group. After eight weeks of aloe formula treatment, TG levels in the liver and plasma decreased significantly; however, plasma cholesterol levels remained unchanged. In agreement with this, a histological analysis revealed that lipid droplets in the liver, which were numerous in the HFD group, completely disappeared after aloe formula supplementation (Fig. 4A) and gene expression of fatty acid synthesis enzymes, FAS, SCD-1, SREBP1a, and GPAT had decreased, particularly in the Aloe QDM complex group as compared to the HFD 
A

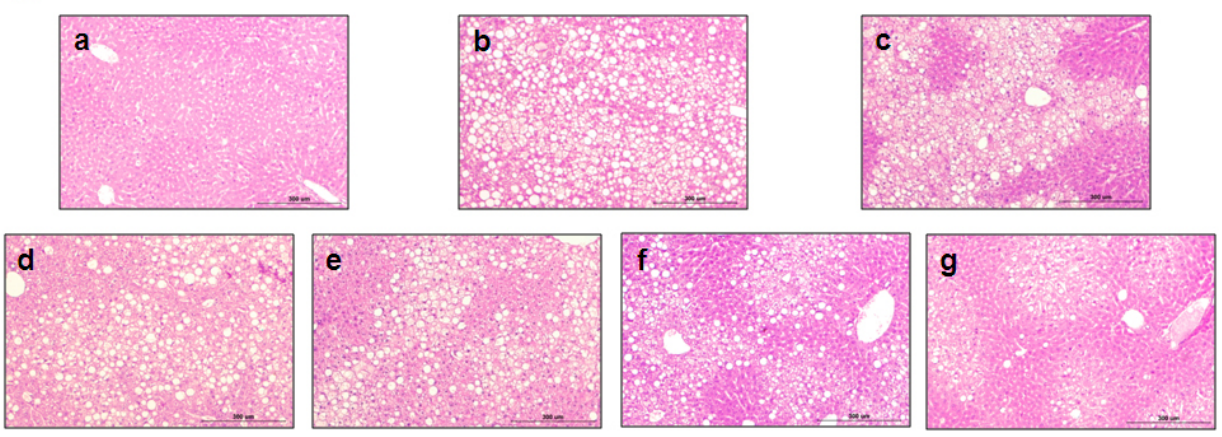

B
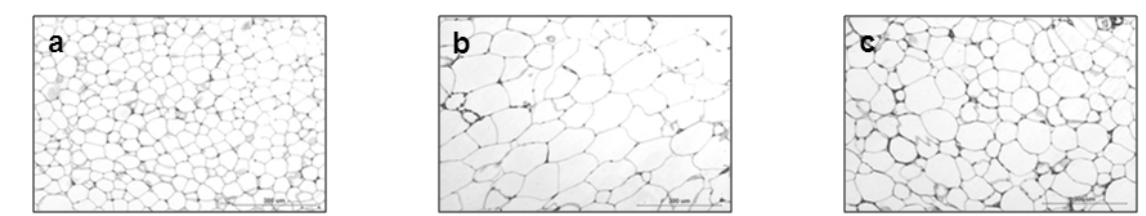

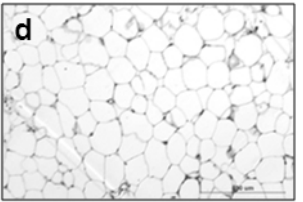

C

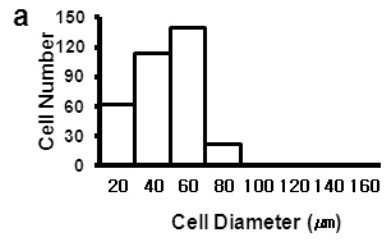

b
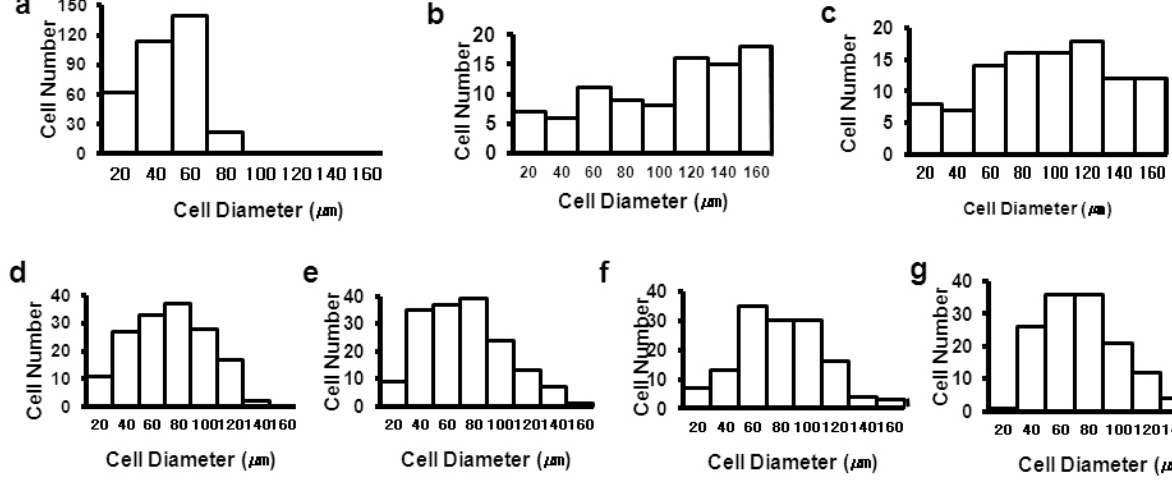

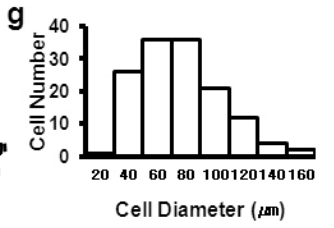

Fig. 4. Histological observations in liver and WAT tissues. At the end of the experimental period, $(A)$ fatty liver and (B) epididymal fat pads were isolated from representative mice of each group, sectioned, and then stained with hematoxylin and eosin. Photomicrographs are of tissues isolated from RD-fed mice (a), untreated HFD mice (b), PGZ (c), PAG (d), ALS (e), Aloe QDM (f), and Aloe QDM complex -treated HFD mice (g). Photomicrographs were taken at a magnification of $\times 200$. (C) The number of the adipocytes in $7.35 \mathrm{~mm}^{2}$ was calculated from the results of $(B)$. group (Fig. 5A).

\section{Reduction of fat mass and periepididymal fat pad morphology}

The mean body weight of animals in the HFD-fed group was not significantly different than in the RD-fed group, and the HFD-fed group showed a $25 \%$ decrease in periepididymal fat pad cell number as compared to RD-fed mice (data not shown). Histological analysis of periepididymal fat pads further confirmed this result and indicated that increases in the adipocyte size of periepididymal fat pads in HFD-fed mice resulted mainly from an accumulation of lipids (Fig. 4B). On the other hand, the average size of adipocytes in periepididymal fat pads of mice treated with aloe formula, PAG, ALS, Aloe QDM, and Aloe QDM complex decreased by $44,47,42$, and $50 \%$, respectively (Fig. 4C). In agreement with this, changes in mRNA expression of fatty acid synthesis enzymes decreased in the aloe formula group, but not in the PGZ group (Fig. 5B).

\section{DISCUSSION}

Herbal prescriptions have been recognized as potentially valid by the scientific medical establishment, and their use has shown steady increases. Since traditional herbal prescriptions are generally prepared from a combination of crude drugs on the basis of oriental prescriptions and herbology, they may have combined effects that differ from 
A

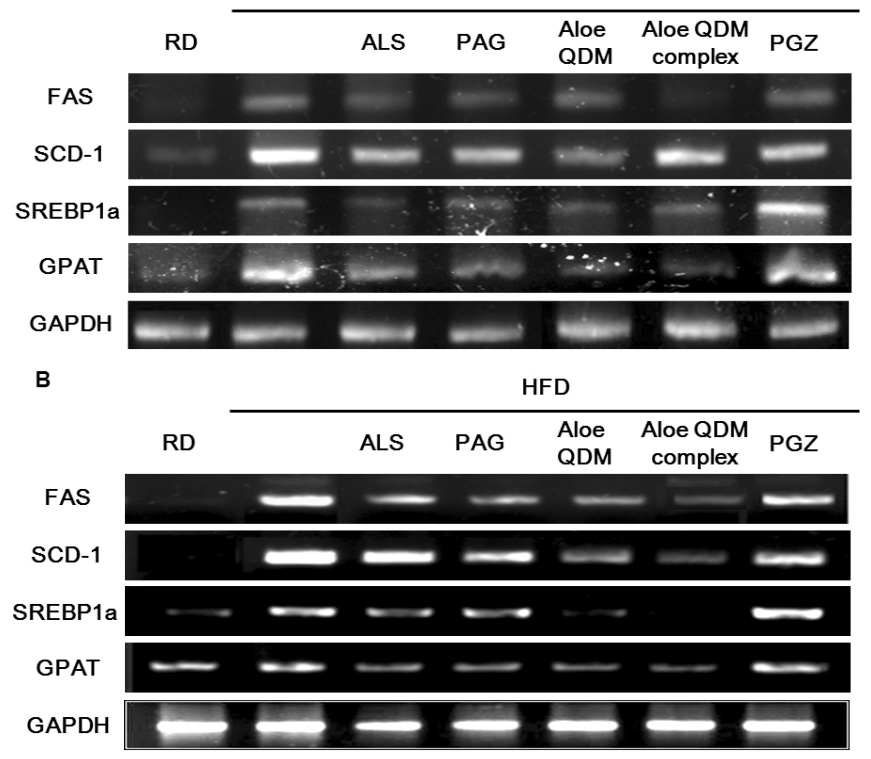

Fig. 5. Change in mRNA expression of fatty acid synthesis enzyme in selected tissues. Lysate from (A) liver and (B) WAT tissues of HFD-fed mice fed with aloe formula or pioglitazone (PGZ). Total RNA was prepared for RT-PCR analysis of the expression of fatty acid synthesis enzyme in tissues. RNA was detected by agarose gel electrophoresis, as described in Materials and Methods. PCR for GAPDH was performed to verify that the initial cDNA contents of the samples were similar. This was repeated in triplicate and similar results were obtained in all three.

the sum of the effects of their individual constituents (Kim et al., 2009a).

We previously demonstrated that PAG improved the insulin resistance in DIO mice (Kim et al., 2009b). These findings led to the assumption that an aloe formula showing high hypoglycemia and hypolipidemia activities would be beneficial for the improvement of insulin resistance in a T2D model. In particular, our results demonstrated that the administration of aloe formula, Aloe QDM complex, to DIO mice prevented the development of T2D-related symptoms.

The administration of aloe formula to HFD-fed mice reduced blood glucose concentration to normal levels despite being continued throughout the 8-week treatment period (Fig. 1). The current understanding of disease progression in T2D is that insulin resistance in peripheral tissues leads to compensatory hyperinsulinemia followed by $\beta$-cell failure (DeFronzo et al., 1992). In the present study, it was found that aloe formula, and in particular the Aloe QDM complex significantly improved insulin resistance (Fig. 3). These results showed that aloe formula increased insulin sensitivity by decreasing blood glucose and insulin levels. Improved blood glucose homeostasis was also ob- served through IPGTT in aloe formula-treated HFD-fed mice (Fig. 2).

High-fat intake and increased levels of free fatty acids in the circulation lead to insulin resistance. Oral administration of aloe formula reduced plasma and hepatic lipid levels in DIO mice (Table I). Thus, we are tempted to speculate that the reduction in plasma levels and in hepatic TG concentrations induced by the aloe formula ameliorated insulin resistance. We then examined the mRNA expression of adipogenic genes in liver by semiquantitive RT-PCR to determine whether aloe formula reduced lipogenesis. It was found that aloe formula and in particular, the Aloe QDM complex, suppressed the expressions of the adipogenesis genes, FAS, SCD-1, SREBP1a, and GPAT (Fig, $5 A$ ), suggesting that the aloe formula may be able to improve insulin resistance through a reduction of fat in the liver.

The histology of adipose tissue from both PGZ-and Aloe QDM complex-treated groups exhibited a similar pattern and it was observed that the relative numbers of adipocytes in the Aloe QDM complex-treated group was higher than in HFD-fed mice (Fig. 4B, C). In agreement with this, gene expression related to adipogenesis was significantly suppressed in the Aloe QDM complex group, but not in the PGZ group (Fig. 5B).

Most of the data, and particularly those relating to the Aloe QDM complex, indicate a significant improvement in insulin resistance and the suppression of mRNA expression of fatty acid synthesis enzymes in WAT, suggesting that $\mathrm{Cr}$ supplementation with the aloe formula may support glucose uptake and lead to the regulation of insulin homeostasis in DIO mice.

In conclusion, the present investigation showed that the aloe formula possessed functional properties, such as modulation of hyperglycemia hyperlipidemia, reduction of blood glucose levels, and adipogenesis of adipose tissue in HFD-fed mice. Our findings suggest that aloe formula and in particular Aloe QDM complex, is a useful dietary phytochemical for improving obesity-related metabolic disorders such as insulin resistance.

\section{ACKNOWLEDGMENTS}

This work was supported by Univera, Inc. as one of CAP projects and also by the Sahmyook University Research fund in 2010.

\section{REFERENCES}

Agarwal, O. P. (1985). Prevention of atheromatous heart disease. Angiology 36, 485-492. 
Anderson, R. A. (1993). Recent advances in the clinical and biochemical effects of chromium deficiency. Prog. Clin. Biol. Res. 380, 221-234.

Anderson, R. A. (1995). Chromium, glucose tolerance, diabetes and lipid metabolism. J. Adv. Med. 8, 37-49.

Attele, A. S., Zhou, Y. P., Xie, J. T., Wu, J. A., Zhang, L., Dey, L., Pugh, W., Rue, P. A., Polonsky, K. S. and Yuan, C. S. (2002). Antidiabetic effects of Panax ginseng berry extract and the identification of an effective component. Diabete 51, 18511858.

DeFronzo, R. A., Bonadonna, R. C. and Ferrannini, E. (1992). Pathogenesis of NIDDM. A balanced overview. Diabetes Care. 15, 318-368.

Eizirik, D. L., Colli, M. L. and Ortis, F. (2009). The role of inflammation in insulitis and beta-cell loss in type 1 diabetes. Nat. Rev. Endocrinol. 5, 219-226.

Folch, J., Less, M. and Sloane Stanley, G. H. (1957). A simple method for the isolation and purification of total lipides from animal tissues. J. Biol. Chem. 226, 497-509.

Hu, F. B., Manson, J. E., Stampfer, M. J., Colditz, G., Liu, S., Solomon, C. G. and Willett, W. C. (2001). Diet, lifestyle, and the risk of type 2 diabetes mellitus in women. $N$. Engl. J. Med. 345, 790-797.

Jullien, D. (2008). Pathogenesis of the metabolic syndrome. Ann. Dermatol. Venereol. 135, 243-248.

Katsuki, A., Sumida, Y., Gabazza, E. C., Murashima, S., Furuta, M., Araki-Sasaki, R., Hori, Y., Yano, Y. and Adachi, Y. (2001). Homeostasis model assessment is a reliable indicator of insulin resistance during follow-up of patients with type 2 diabetes. Diabetes Care 24, 362-365.

Kim, J. O., Kim, K. S., Lee, G. D., and Kwon, J. H. (2009a). Antihyperglycemic and antioxidative effects of new herbal formula in streptozotocin-induced diabetic rats. J. Med. Food 12, 728-735

Kim, K., Kim, H., Kwon, J., Lee, S., Kong, H., Im, S. A., Lee, Y. H., Lee, Y. R., Oh, S. T., Jo, T. H., Park, Y. I., Lee, C. K. and Kim, K. (2009b). Hypoglycemic and hypolipidemic effects of processed Aloe vera gel in a mouse model of non-insulin-dependent diabetes mellitus. Phytomedicine 16 856-863.

Klein, A. D. and Penneys, N. (1988). Aloe vera. J. Am. Acad.
Dermatol. 18, 714-720.

Libby, P., Ridker, P. M. and Maseri, A. (2002). Inflammation and atherosclerosis. Circulation 105, 1135-1143.

Marcovecchio, M., Mohn, A. and Chiarelli, F. (2005). Type 2 diabetes mellitus in children and adolescents. J. Endocrinol. Invest. 28, 853-863.

Mertz, W. (1993). Chromium in human nutrition: a review. J. Nutr. 123, 626-633.

Mertz, W. and Schwarz, K. (1959). Relation of glucose tolerance factor to impaired intravenous glucose tolerance of rats on stock diets. Am. J. Physiol. 196, 614-6108.

Omodeo Salè, F., Marchesini, S., Fishman, P. H. and Berra, B. (1984). A sensitive enzymatic assay for determination of cholesterol in lipid extracts. Anal. Biochem. 142, 347-350.

Reynolds, T. and Dweck, A. C. (1999). Aloe vera leaf gel: a review update. J. Ethnopharmacol. 68, 3-37.

Rosenbloom, A. L., Joe, J. R., Young, R. S. and Winter, W. E. (1999). Emerging epidemic of type 2 diabetes in youth. Diabetes Care 22, 345-354.

Schwarz, K. and Mertz, W. (1959). Chromium (III) and the glucose tolerance factor. Arch. Biochem. Biophys. 85, 292-295.

Srikanta, S., Ganda, O. P., Jackson, R. A., Gleason, R. E., Kaldany, A., Garovoy, M. R., Milford, E. L., Carpenter, C. B., Soeldner, J. S. and Eisenbarth, G. S. (1983). Type I diabetes mellitus in monozygotic twins: chronic progressive beta cell dysfunction. Ann. Intern. Med. 99, 320-326.

Weyer, C., Funahashi, T., Tanaka, S., Hotta, K., Matsuzawa, Y., Pratley, R. E. and Tataranni, P. A. (2001). Hypoadiponectinemia in obesity and type 2 diabetes: close association with insulin resistance and hyperinsulinemia. J. Clin. Endocrinol. Metab. 86, 1930-1935.

Xie, J. T., Aung, H. H., Wu, J. A., Attel, A. S. and Yuan, C. S. (2002). Effects of American ginseng berry extract on blood glucose levels in ob/ob mice. Am. J. Chin. Med. 30, 187-194.

Zhang, C. Y., Baffy, G., Perret, P., Krauss, S., Peroni, O., Grujic D., Hagen, T., Vidal-Puig, A. J., Boss, O., Kim, Y. B., Zheng, X. X., Wheeler, M. B., Shulman, G. I., Chan, C. B. and Lowell, B. B. (2001). Uncoupling protein-2 negatively regulates insulin secretion and is a major link between obesity, beta cell dysfunction, and type 2 diabetes. Cell 105, 745-755. 